\title{
EFEKTIFITAS PENGGUNAAN TEKNIK RELAKSASI OTOT PROGRESIF DALAM MENURUNKAN TINGKAT NYERI PASIEN GASTRITIS DI RUMAH SAKIT DAERAH MADANI PALU
}

\author{
Iwayan Supetran \\ Politeknik Kesehatan Kementerian Kesehatan Palu
}

\begin{abstract}
ABSTRAK
Nyeri merupakan salah satu manifestasi klinis yang terjadi pada pasien gastritis. Nyeri yang dirasakan adalah nyeri ulu hati atau nyeri epigastrium. Dalam riset tentang intervensi keperawatan relaksasi otot progresif dapat membuat tubuh dan pikiran terasa tenang, rileks, dan lebih mudah untuk tidur (Davis, 2005).Penatalaksanaan nonfarmakologis saat ini sangat dianjurkan, karena tidak menimbulkan efek samping, dan dapat memandirikan pasien gastritis yang mengalami nyeri untuk dapat menjaga kesehatannya. Salah satu pengobatan secara non farmakologis dalam mengatasi nyeri menurut para ahli diantaranya adalah teknik relaksasi otot progresif. Tujuan penelitian ini adalah diketahuinya efektifitas penggunaan teknik relaksasi otot progresif dalam menurunkan tingkat nyeri pasien gastritis di Ruang Jambu Rumah Sakit Daerah Madani.

Penelitian ini merupakan penelitian Preexperimental design dengan pendekatan pretest-posttest design. Populasi dalam penelitian ini adalah semua penderita gastritis yang dirawat di Ruang Jambu pada tahun 2015.Sampel dalam penelitian ini sebanyak 12 orang, teknik pengambilan sampel purposive sampling. Analisis yang digunakan dalam penelitian ini adalah analisis univariat dan bivariat dengan Uji statistik yang digunakan adalah uji wilcoxon.

Dari 12 respoden sebelum diberikan perlakuan diberikan relaksasi otot progresif pasien gastritis yang mengalami nyeri sebanyak 12 respoden (100\%). Setelah diberikan perlakuan diberikan relaksasi otot progresif pasien gastritis yang mengalami nyeri sebanyak 3 respoden (25\%) dan yang tidak mengalami nyeri sebanyak 9 respoden (75\%). Hasil test statistik menunjukan hasil uji Wilcoxon diperoleh nilai sig. 0,002 ( $<<$ $0,05)$, artinya "teknik relaksasi otot progresif sangat efektif dalam menurunkan tingkat nyeri pasien gastritis di Ruang Jambu Rumah Sakit Daerah Madani"

Pasien gastritis sebelum diberikan relaksasi otot progresif semuanya mengalami nyeri, sedangkan setelah diberikan relaksasi otot progresif sebagian besar tidak mengalami nyeri, dari hasil penelitian ini dapat disimpulkan ada perbedaan tingkat nyeri sebelum dan sesudah dilakukan teknik relaksasi otot progresif dalam menurunkan tingkat nyeri pasien gastritis di Ruang Jambu Rumah Sakit Daerah Madani.
\end{abstract}

Kata Kunci: Nyeri, gastritis, relaksasi otot progresif

Referensi : 18 (2005-2013)

\section{PENDAHULUAN}

Salah satu masalah kesehatan yang kita hadapi sekarang ini adalah penyakit saluran pencernaan seperti gastitis. Masyarakat pada umumnya mengenal gastritis dengan sebutan penyakit maag yaitu penyakit yang menurut mereka bukan suatu masalah yang besar, misalnya jika merasakan nyeri perut maka mereka akan langsung mengatasinya dengan makan nasi, kemudian nyerinya hilang. Penyakit gastritis ini bila tidak di atasi dengan cepat maka dapat menimbulkan perdarahan (hemorrhagic gastritis) sehingga banyak darah yang keluar dan berkumpul di lambung, selain itu juga dapat menimbulkan tukak lambung, 
kanker lambung sehingga dapat menyebabkan kematian (Hastuti, 2007). Badan penelitian kesehatan dunia WHO mengadakan tinjauan terhadap beberapa negara dunia dan mendapatkan hasil persentase dari angka kejadian gastritis di dunia, diantaranya Inggris 22\%, China $31 \%$, Jepang $14,5 \%$, Kanada 35\%, dan Perancis 29,5\%. Di dunia, insiden gastritis sekitar 1,8-2,1 juta dari jumlah penduduk setiap tahun. Insiden terjadinya gastritis di Asia Tenggara sekitar 583.635 dari jumlah penduduk setiap tahunnya. Prevalensi gastritis yang dikonfirmasi melalui endoskopi pada populasi di Shanghai sekitar 17,2\% yang secara substantial lebih tinggi daripada populasi di barat yang berkisar $4,1 \%$ dan bersifat asimptomatik. Gastritis biasanya dianggap sebagai suatu hal yang remeh namun gastritis merupakan awal dari sebuah penyakit yang dapat menyusahkan kita. Persentase dari angka kejadian gastritis di Indonesia menurut WHO adalah 40,8\%. Angka kejadian gastritis pada beberapa daerah di Indonesia cukup tinggi dengan prevalensi 274,396 kasus dari 238,452,952 jiwa penduduk (Kurnia dan Rahmi, 2014).

Penyakit gastritis merupakan penyakit saluran pencernaan bagian atas yang banyak dikeluhkan dimasyarakat dan paling banyak ditemukan di bagian gastroenterologi, diperkirakan hampir semua penderita gastritis mengalami kekambuhan. Salah satu faktor yang dapat menimbulkan munculnya gejala gastritis adalah stres dan kebiasaan mengkonsumsi makanan yang bisa meningkatkan asam lambung (Maulidah, 2006).

Nyeri merupakan salah satu manifestasi klinis yang terjadi pada pasien gastritis. Nyeri yang dirasakan adalah nyeri ulu hati atau nyeri epigastrium. Nyeri adalah pengalaman sensori dan emosional yang tidak menyenangkan akibat kerusakan jaringan yang aktual dan potensial (Price, 2006). Secara umum tanda dan gejala yang sering terjadi pada pasien yang mengalami nyeri dapat tercermin dari perilaku pasien misalnya suara (menangis, merintih, menghembuskan nafas), ekspresi wajah (meringis, menggigit bibir), pergerakan tubuh (gelisah, otot tegang, mondar-mandir, dlI), interaksi sosial (menghindari percakapan, disorientasi waktu) (Judha, 2012).

Secara garis besar nyeri dibagi menjadi 2 yaitu nyeri akut dan nyeri kronis. Nyeri akut biasanya awitannya tiba-tiba dan umumnya berkaitan dengan cedera spesifik, waktunya kurang dari enam bulan dan biasanya kurang dari satu bulan. Nyeri kronik adalah nyeri konstan atau intermiten yang menetap sepanjang suatu periode waktu. Nyeri kronis berlangsung selama enam bulan atau lebih (Potter \& Perry, 2006).

Data dari medikal rekord Rumah Sakit Daerah Madani Proponsi Sulawesi Tengah pada tahun 2015 jumlah pasien gastritis yang rawat jalan sebanyak 300 orang, jumlah pasien gastritis rawat inap sebanyak 230 orang, dari kasus tersebut semuanya pasien merasakan nyeri ulu hati,selain tindakan pemberian therapi medis sangat dimungkinkan untuk Penatalaksanaan nonfarmakologis saat ini karena tidak menimbulkan efek samping, dan dapat memandirikan penderita gastritis untuk dapat menjaga kesehatan mereka sendiri. Salah satu pengobatan secara non farmakologis dalam mengatasi nyeri adalah teknik relaksasi otot progresif. Latihan relaksasi otot progresif dapat memberikan pemijitan halus pada berbagai kelenjerkelenjer pada tubuh, menurunkan produksi kortisol dalam darah, mengembalikan pengeluaran hormon yang secukupnya sehingga memberi keseimbangan emosi dan ketenangan pikiran (Purwoto, 2007). Penelitian ini bertujuan untuk mengetahui efektifitas penggunaan teknik relaksasi otot progresif dalam menurunkan tingkat nyeri pasien gastritis di Ruang Jambu Rumah Sakit Daerah Madani. 


\section{METODE PENELITIAN \\ Jenis Penelitian}

Jenis penelitian yang digunakan yaitu Preexperimental design dengan pendekatan pretest-posttest design. Pretest-posttest design adalah penelitian yang dilakukan dengan cara memberikan pengamatan awal terlebih dahulu sebelum diberikan intervensi, setelah itu diberikan intervensi, kemudian dilakukan pengamatan akhir (Alimul. A. 2007).

\section{Populasi dan Sampel}

\section{Populasi}

Populasi adalah keseluruhan objek penelitian atau yang diteliti (Notoatmodjo, 2010). Populasi dalam penelitian ini adalah semua penderita gastritis yang dirawat di Ruang Jambu Rumah Sakit Daerah Madani Palu pada tahun 2014.

\section{Sampel}

Sampel adalah bagian dari jumlah dan karakteristik yang dimiliki oleh populasi (Sugiyono, 2007). Sampel dalam penelitian ini adalah pasien yang dirawat di Ruang jambu Rumah Sakit Daerah Madani Palu pada saat penelitian dilakukan. Besar sampel dalam penelitian ini diperoleh dari hasil perhitungan dengan rumus estimasi yang dimana populasi tidak diketahui:

$$
n=\frac{Z_{1-\alpha / 2}^{2} P(1-P)}{d^{2}}
$$

Keterangan :

$\mathrm{n} \quad=$ jumlahsampel

$Z^{2}=$ nilai table $Z=0.05$ adalah 1,96

$\mathrm{p} \quad=$ presisi $=0,5$

d = Tingkat kesalahan $20 \%=0,2$

Teknik pengambilan sampel dalam penelitian ini adalah non random sampling dengan pendekatan purposive sampling.

D. Hipotesis

ada pengaruh penggunaan teknik relaksasi otot progresif dalam menurunkan tingkat nyeri pasien gastritis di Ruang Jambu Rumah Sakit Daerah Madani.

\section{E. Teknik Pengumpulan Data}

\section{Data Primer}

Data primer yaitu data yang dikumpulkan melalui wawancara tidak langsung dengan menggunakan kuesioner. Penggunaan kuesioner merupakan salah satu metode pengumpulan data yang digunakan untuk memperoleh informasi dan juga mengungkapkan hal-hal yang diketahui responden (Riwidikdo, 2009).

Pada kuesioner nyeri menggunakan skala analog deskritif, dengan kriteria:

0 : Tidak nyeri

1-3 : Nyeri ringan : secara obyektif klien dapat berkomunikasi dengan baik.

4-6 : Nyeri sedang : Secara obyektif klien mendesis, menyeringai, dapat menunjukkan lokasi nyeri, dapat mendeskripsikannya, dapat mengikuti perintah dengan baik.

7-9 : Nyeri berat : secara obyektif klien terkadang tidak dapat mengikuti perintah tapi masih respon terhadap tindakan, dapat menunjukkan lokasi nyeri, tidak dapat mendeskripsikannya, tidak dapat diatasi dengan alih posisi nafas panjang dan distraksi

10 : Nyeri sangat berat : Pasien sudah tidak mampu lagi berkomunikasi, memukul.

\section{Data Sekunder}

Data sekunder adalah data penderita gastritis yang diperoleh dari Rumah Sakit Daerah Madani, data Kementrian Kesehatan Republik 
Indonesia, data Word Health Organization (WHO).

\section{F. Analisa Data}

Dilakukan untuk mengetahui distribusi frekuensi dan proporsi masing-masing yang diteliti, dan di analisi untuk melihat pengaruh antara variabel bebas dengan terikat, dengan nilai kemaknaan 0,05 dengan tingkat kepercayaan 95\%. Adapun uji yang digunakan pada penelitian ini adalah uji wilcoxon dengan rumus sebagai berikut:

$$
\mathrm{Z}=\frac{T-\left[\frac{1}{4 N(N+1)}\right]}{\sqrt{\frac{1}{24 N(N+1)(2 N+1)}}}
$$

Keterangan :

$\mathrm{N}=$ banyak data yang berubah setelah diberi perlakuan berbeda

Tabel .1

Distribusi Frekuensi Karakteristik Responden Menurut Pendidikan Pasien Gastritis di Ruang Jambu Rumah Sakit Daerah Madani Tahun 2015

\begin{tabular}{lll}
\hline Pendidikan & Frekuensi (f) & Presentase (\%) \\
\hline Pendidikan dasar (SD, SMP) & 4 & 33,3 \\
Pendidikan menengah (SMA) & 5 & 41,7 \\
Pendidikan tinggi & 3 & 25 \\
\hline Jumlah & $\mathbf{1 2}$ & $\mathbf{1 0 0}$
\end{tabular}

Sumber: Data primer
2. Karakteristik berdasarkan pekerjaan

Untuk memperoleh distribusi karakteristik responden menurut

Tabel. 2

Distribusi Frekuensi Karakteristik Responden Menurut Pekerjaan Pasien Gastritis di Ruang Jambu Rumah Sakit Daerah Madani Tahun 2015

pekerjaan dapat dilihat pada tabel berikut:

\begin{tabular}{lll}
\hline Pekerjaan & Frekuensi (f) & Presentase (\%) \\
\hline Bekerja & 7 & 58,3 \\
Tidak Bekerja & 5 & 41,7 \\
\hline Jumlah & $\mathbf{1 2}$ & $\mathbf{1 0 0}$ \\
\hline
\end{tabular}

Sumber: Data primer
Berdasarkan Tabel 2, dari 38 respoden yang bekerja sebanyak 7
$\mathrm{T}=$ jumlah renking dari nilai selisih yng negative (apabila banyaknya selisih yang positif lebih banyak dari banyaknya selisih negatif = jumlah ranking dari nilai selisih yang positif (apabila banyaknya selisih yang negatif > banyaknya selisih yang positif)

HASIL

Penelitian ini dilaksanakan pada tanggal 05 Mei sampai 07 Juli 2015 di Ruang Jambu Rumah Sakit Daerah Madani Propinsi Sulawesi Tengah. Adapunjumlahsampelyaitu12 responden. Analisa yang digunakan dalam penelitian ini adalah analisa univariat dan analisa bivariat.

1. Karakteristik berdasarkan pendidikan

Untuk memperoleh distribusi karakteristik responden menurut pendidikan dapat dilihat pada tabel berikut:

responden responden

(n)


Tabel 3.

Distribusi Gambaran Nyeri Pasien Gastritis Sebelum dan Sesudah Diberikan Relaksasi Otot Progresif Di Ruang Jambu Rumah Sakit Daerah Madani

Propinsi Sulawesi Tengah Tahun 2015

\begin{tabular}{cllll}
\hline \multirow{2}{*}{ Kriteria } & \multicolumn{2}{l}{$\begin{array}{l}\text { Sebelum } \\
\text { Relaksasi Otot Progresif }\end{array}$} & \begin{tabular}{l} 
Diberikan \\
\cline { 2 - 5 }
\end{tabular} & $\begin{array}{l}\text { Setelah } \\
\text { Relaksasi Otot Progresif }\end{array}$ \\
\cline { 2 - 5 } & (f) & $\begin{array}{l}\text { Diberikan } \\
(\%)\end{array}$ & $\begin{array}{l}\text { Freknensi } \\
(\mathrm{f})\end{array}$ & $\begin{array}{l}\text { Presentase } \\
(\%)\end{array}$ \\
\hline $\begin{array}{l}\text { Nyeri } \\
\text { Tidak }\end{array}$ & 12 & 100 & 3 & 25 \\
Nyeri & 0 & 0 & 9 & 75 \\
\hline Jumlah & $\mathbf{1 2}$ & $\mathbf{1 0 0}$ & $\mathbf{1 2}$ & $\mathbf{1 0 0}$ \\
\hline
\end{tabular}

Sumber: Data primer

\section{Analisisis Bivariat}

Gambaran Nyeri Pasien Gastritis Sebelum dan Sesudah Diberikan Relaksasi Otot Progresif

$$
\text { Tabel . } 4
$$

Efektifitas Penggunaan Teknik Relaksasi Otot Progresif Dalam Menurunkan Tingkat Nyeri Pasien Gastritis di Ruang Jambu Rumah Sakit Daerah Madani Tahun 2015

\begin{tabular}{cll}
\hline Pre test-post test & Mean Rank & Nilai $P$ \\
\hline Nyeri Pasien Gastritis & 6,50 & 0,002 \\
\hline Sumber: Data primer & &
\end{tabular}

Hasil

test statistikmenunjukanhasilujiwilcoxondi perolehnilaiMean Rank 6,5 dan nilai $\mathrm{p} \quad 0,002 \quad(P \leq 0,05)$, dengandemikiansecara statistik teknik relaksasi otot progresif sangat efektif dalam menurunkan tingkat nyeri pasien gastritis di Ruang Jambu Rumah Sakit Daerah Madani.

\section{PEMBAHASAN}

1. Gambaran nyeri pasien gastritis sebelum diberikan tehnik relaksasi otot progresif

Hasil penelitian menunjukkan sebelum diberikan tehnik relaksasi otot progresif semuanya pasien mengalami nyeri. Rasa nyeri yang ditunjukkan merupakan akibat respon tubuh terhadap trauma atau akibat mukosa lambung mengalami kerusakan. Persarafan lambung sepenuhnya berasal dari system sarafotonom. Suplai saraf parasimpatis untuk lambung dan duodenum dihantarkan ke dan dari abdomen melalui saraf vagus. Persarafan simpatism elalui saraf splanchnicus major dan ganglia siliaka. Serabut-serabut aferen menghantarkan impul snyeri yang dirangsang oleh peregangan, kontraksiotot, sertaperadangan, dandirasakan di daerah epigastrium abdomen. Serabut-serabut eferen simpatis menghambat motilitas dan sekresi lambung. Pleksus saraf mienterikus (auerbach) dan submukosa (meissner)

membentuk persarafan intrinsic dinding lambung dan mengoordinasi aktivitas motorik dan sekresi mukosa lambung.

Sejalan dengan pendapat Abraham (2010), yang menyatakan pada penderita gastritis pertama kali yang terjadi adalah membran mukosa lambung menjadi edema dan hipermik (kongesti dengan jaringan, cairan dan darah) dan mengalami erosi superfisial, bagian ini mensekresi 
sejumlah getah lambung yang mengandung sangat sedikit asam tetapi banyak mukus. Ulserasi superfisial dapat terjadi dan dapat menumbulkan hemoragi. Pasien dapat mengalami ketidaknyamanan, sakit kepala, malas, mual dan anoreksia, sering disertai mual dan cegukan.

\section{Gambaran nyeri pasien gastritis setelah diberikan tehnik relaksasi otot progresif}

Hasil penelitian menunjukkan setelah diberikan relaksasi otot progresif sebagian besar pasien sudah tidak mengalami nyeri.setelah diberikan relaksasi otot progresif pasien merasakan nyerinya berkurang, karena gerakan-gerakan yang telah diberikan secara perlahan membantu merilekskan sinap-sinap saraf baik yang simpatis maupun yang parasimpatis. Saraf yang rileks menurunkan rasa nyeri secara perlahan.

Sejalan dengan pendapat Ganong (2010), yang menyataan sekresi asam lambung dipengaruhi oleh kerja saraf dan hormon. Sistem saraf yang bekerja yaitu saraf pusat dan saraf otonom, yakni saraf simpatis dan parasimpatis. Adapun hormon yang bekerja antara lain adalah hormon gastrin, asetilkolin, dan histamin. Terdapat tiga fase yang menyebabkan sekresi asam lambung. Pertama, fase sefalik, sekresi asam lambung terjadi meskipun makanan belum masuk lambung, akibat memikirkan atau merasakan makanan. Kedua, fasegastrik, ketika makanan masuk lambung akan merangsang mekanisme sekresi asam lambung yang berlangsung selama beberapa jam, selama makanan masih berada di dalam lambung. Ketiga, fase intestinal, proses sekresi asam lambung terjadi ketika makanan mengenai mukosausus. Produksi asam lambung akan tetap berlangsung meskipun dalam kondisi tidur. Kebiasaan makan yang teratur sangat penting bagi sekresi asam lambung karena kondisi tersebut memudahkan lambung mengenali waktu makan sehingga produksi lambung terkontrol.

\section{Efektifitas penggunaan teknik} relaksasi otot progresif dalam menurunkan tingkat nyeri pasien gastritis di Ruang Jambu Rumah Sakit Daerah Madani. Peneliti ini membuktikan sebelum diberikan relaksasi otot progresif pasien gastritis yang mengalami nyeri dikarenakan oleh perhatian pasien masih terfokus pada titik nyeri sehingga pasien merasakan nyeri yang hebat. Sedangkan setelah diberikan relaksasi otot progresif pasien gastritis mengalami penurunan skala nyeri karena pasien sudah tidak terfokus lagi pada rasa sakitnya itu. Sehingga hipotalamus tidak mengaktifkan mediator nyeri.

Hasil penelitian ini sejalan dengan penelitian Melisa (2013), tentang efektivitas pemberian teknik relaksasi progresif dalam penurunan nyeri pasien gastritis akut di RSUD Muara Teweh 2013 dengan hasil dari 25 responden tingkat nyeri pada pasien gastritis akut sebelum pemberian teknik relaksasi progresif adalah nyeri ringan sebanyak 4 orang (16\%), nyeri sedang yaitu sebanyak 16 orang (64 $\%$ ), nyeri berat terkontrol sebanyak 5 orang (20\%). Tingkat nyeri pada pasien gastritis akut sesudah pemberian teknik relaksasi progresif adalah tidak ada nyeri sebanyak 1 orang (4\%), nyeri ringan sebanyak 12 orang (48\%), nyeri sedang yaitu sebanyak 7 orang (28\%), nyeri berat terkontrol sebanyak 5 orang (20\%). Nilai sum ranks menunjukkan bahwa nilai rank untuk tingkat nyeri pada sebelum pemberian teknik relaksasi progresif adalah sebesar 71,50 pada saat sedangkan saat sesudah 
pemberian teknik relaksasi progresif adalah sebesar 6,50. Nilai Z sebesar 2,887 dengan nilai signifikan sebesar 0,004 .

Pendapat Judha (2012), menyatakan nyeri merupakan salah satu manifestasi klinis yang terjadi pada pasien gastritis. Nyeri yang dirasakan adalah nyeri ulu hati atau nyeri epigastrium. Nyeri adalah pengalaman sensori dan emosional yang tidak menyenangkan akibat kerusakan jaringan yang aktual dan potensial. Secara umum tanda dan gejala yang sering terjadi pada pasien yang mengalami nyeri dapat tercermin dari perilaku pasien misalnya suara (menangis, merintih, menghembuskan nafas), ekspresi wajah (meringis, menggigit bibir), pergerakan tubuh (gelisah, otot tegang, mondar-mandir), interaksi sosial (menghindari percakapan, disorientasi waktu).

Pendapat Smeltzer dan Bare (2008) relaksasi otot skeletal dipercaya dapat menurunkan nyeri dengan merilekskan ketegangan otot yang menunjang nyeri. Hampir semua orang dengan nyeri kronis mendapatkan manfaat dari metode relaksasi. Periode relaksasi yang teratur dapat membantu untuk melawan keletihan dan ketegangan otot yang terjadi dengan nyeri kronis dan yang meningkatkan nyeri.

Pendapat Melzack dan Wall (1965), teori gate control dari mengusulkan bahwa impuls nyeri dapat diatur atau dihambat oleh mekanisme pertahanan di sepanjang sistem saraf pusat. Teori ini mengatakan bahwa impuls nyeri dihantarkan saat sebuah pertahanan dibuka dan impuls dihambat saat sebuah pertahanan tertutup. Upaya menutup pertahanan tersebut merupakan dasar teori menghilangkan nyeri.

\section{KESIMPULAN}

Berdasarkan hasil penelitian efektifitas penggunaan teknik relaksasi otot progresif dalam menurunkan tingkat nyeri pasien gastritis di Ruang Jambu Rumah Sakit Daerah Madani, maka dapat disimpulkan:

1. Gambaran nyeri pasien gastritis sebelum diberikan tehnik relaksasi otot progresif sebagian besar mengalami nyeri

2. Gambaran nyeri pasien gastritis setelah diberikan tehnik relaksasi otot progresif sebagian besar tidak mengalami nyeri

3. Ada perbedaan tingkat nyeri sebelum dan sesudah dilakukan teknik relaksasi otot progresif dalam menurunkan tingkat nyeri pasien gastritis di Ruang Jambu Rumah Sakit Daerah Madani palu.

\section{DAFTAR PUSTAKA}

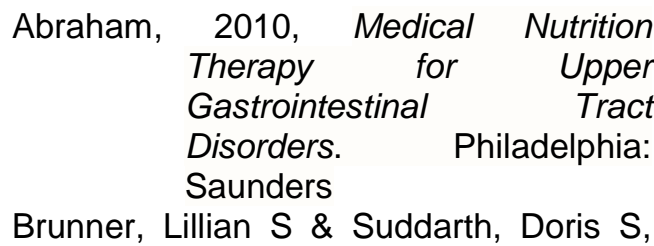
2010, Keperawatan Medikal Bedah Edisi $8 \mathrm{Vol}$ 2. EGC. Jakarta

Corwin, Elisabeth J, 2007, Buku Saku Patofisiologi, EGC, Jakarta.

Ehrlich, 2011, Gangguan Gastrointestinal: Aplikasi Asuhan Keperawatan Mediakl Bedah. Jakarta : Salemba Medika

Ganong, William F. 2010. Buku Ajar Fisiologi Kedokteran. EGC, Jakarta.

Guyton, 2009, Textbook of Medical Physiology. 11th ed. Philadelphia, PA, USA: Elsevier Saunders.

Hastuti, 2007, Faktor-Faktor Risiko Nyeri Epigastrium Pada Penderita Gastritis. Tesis. Mahasiswa Magister Epidemiologi Universitas Diponegoro. 
Jacobson, 2009, Methods For Teachy, Terjemah Ahmad Fawaid Dan Khoirul Anam, Newjersy USA: Preason Education.

Judha, 2012, Teori Pengukuran Nyeri \& Nyeri. Persalinan, Nuha Medika, Yogyakarta

Kozier, 2008, Fundamental Of Nursing; Consept, Process And Practice, (Fourth Edition), EGC, Jakarta.

Murphy, 2006, How to Design Trademarks and Logos. Ohio : North Light Book.

Potter, Patricia A \& Perry, Anne G, 2005, Buku Ajar Fundamental Keperawatan konse, EGC, Jakarta
Riwidikdo, H, 2009, Statistik Kesehatan, Mitra Cendika Press, Yogyakarta

Soeparman, W 2009, IImu Penyakit Dalam jilid I, Edisi kedua, Balai Penerbit FK UI, Jakarta.

Sugiyono, 2007, Stastistik Untuk Penelitian. Alphabeta. Bandung.

Tamsuri, A 2007, Konsep Dan Penatalaksanaan Nyeri, EGC, Jakarta

Tanra, H, 2007, Penanganan Nyeri Kanker, PT. Rineka Cipta, Jakarta.

Tjokronegoro dan Utomo, 2008, Buku Ajar IImu Penyakit Dalam Jilid II. Balai Penerbit FKUI, Jakarta 